\title{
Impact of formative assessment on the outcome of summative assessment - a feedback based cross sectional study conducted among basic science medical students enrolled in MD program
}

\author{
Sanjib Das ${ }^{1}$, Kusai M Alsalhanie ${ }^{2}$, Samal Nauhria ${ }^{3}$, Vivek R Joshi' ${ }^{4}$, Safeer Khan ${ }^{5}$, \\ Vishal Surender ${ }^{6}$
}

\begin{abstract}
${ }^{1}$ Associate Professor, Department of Pharmacology \& Clinical Sciences, ${ }^{2}$ Instructor, Department of Pathophysiology,
${ }^{3}$ Assistant Professor, Department of Pathophysiology, ${ }^{4}$ Associate Professor, Department of Molecular Sciences, ${ }^{5}$ Senior Lecturer, Department of Anatomical Sciences, ${ }^{6}$ Associate Professor, Department of Medical Physiology,

Windsor University School of Medicine, St. Kitts and Nevis, West Indies
\end{abstract}

\section{A B S T R A C T}

Background: Assessment is an integral part of all forms of learning. Formative assessment in different forms have evolved as a mean to find the learning gaps (what students already know in compare to what they need to know). As a result it becomes possible to give appropriate feedback to the students to close this gap. Summative assessment on the other hand is purposefully designed to make judgments about students' performance and produce grades. Aims and Objectives: The main purpose of this study is to explore students' view with regards to the impact of formative assessment on the outcome of summative assessment in basic science MD program. Materials and Methods: A cross sectional descriptive study was conducted involving 142 students of an International medical school. A questionnaire was designed, pretested, and finally used to record different opinions of the students and data was collected, analyzed, and interpreted. Results: Majority of the respondents (78\%) favored that the feedback collected from formative assessment remains important for them as it helps to fill their learning gaps. Respondents by large $(76.8 \%)$ also agreed that formative assessment helps the faculty to identify student's weak point. A huge percentage $(80.8 \%)$ of respondents was in agreement that formative assessment inspires them for deep learning and regular study. However, a fair number of respondents $(36.4 \%)$ thought that frequently scheduled formative assessment impede their independent learning thus negatively impact their performance in summative exam. Conclusion: Formative assessment if scheduled properly can have a positive impact on the summative assessment.

Website:

http://nepjol.info/index.php/AJMS DOI: $10.3126 /$ ajms.v8i4.17161 E-ISSN: 2091-0576 P-ISSN: 2467-9100

Key words: Formative assessment, Summative assessment, Learning gap, Deep learning, Academic performance, Feedback loop

\section{INTRODUCTION}

Assessment is a cornerstone in any medical program. Medical schools, postgraduate programs and licensing authorities have recently put huge efforts on the assessment portion. ${ }^{1}$ The term assessment is generally used to refer to all activities instructors use to help students learn and to gauge students' progress. ${ }^{2}$ It has been known now that assessment, besides being a tool for measuring the students' progress and eligibility to practice medicine, drives learning. Assessment in medical education is broadly categorized into two groups: formative and summative. ${ }^{1}$ 
Formative assessment, for learning assessment, tends to provide students with feedback on their own performance and guide them. It also helps shaping their learning. Typically these types of assessment are carried out concurrently with instructions. Formative assessment aims to see if students understand the instructions before doing a summative assessment. ${ }^{3}$ Its main purpose is to modify teaching and learning to improve students' outcome. It can be of a formal or informal nature. ${ }^{4}$ Formative assessment is conducted throughout the course or learning module. It is not used for decision making on students' academic progress.

On the other hand, summative assessment is that to sum up learning. ${ }^{5}$ It looks at post achievement only. Summative assessment, of learning assessment, is meant to make decisions on students' academic performance including pass/fail decisions or eligibility for licensure. It determines whether the goals of education are being fulfilled. It is typically formal in nature and conducted at the end of the course or learning module.

Several studies have shown the positive impact of formative assessment on the final outcome of medical programs by producing competent physicians. ${ }^{6,7}$ Spolsky and Hult suggested that formative assessment provides feedback for teachers to modify subsequent learning activities and experiences. ${ }^{8}$ Additionally, it aids to identify and remediate students' deficiencies. Cauley and McMillan opiniate that frequent formative assessment allows the students to have a better grasp of learning material. ${ }^{9}$ Furthermore, formative assessment enhances self-regulated learning. ${ }^{10}$

Although several studies support the rationale and importance of formative assessment, only a few specifically aimed to explore the direct impact of formative assessment on the outcome of summative ones in NBME (National Board of Medical Examiners) mapped medical education program set up.

The purpose of this study is to determine the students' view about the impact of formative assessment on the outcome of summative assessment involving basic science students enrolled in MD program. This study hypothesizes that; students overall find that formative assessment has a positive impact on the outcome of summative assessment in the basic science medical education program.

\section{MATERIALS AND METHODS}

This cross sectional descriptive study was carried out over 142 students of an international medical school located in
Saint Kitts in the West Indies. The university had adopted a contextualized, competency-based curriculum mapped with NBME objectives. Students were randomly selected from the second semester through final (fifth) semester of basic science MD program. The school where the study was conducted primarily runs a four-year MD program through ten semesters. Basic science semesters include semesters one to five. Semesters six through ten are the clinical semesters where students perform their rotations in the hospital setting.

Various forms of formative assessments are practiced in included in the institution where this study was carried out. Examples include but not limited to: formative quizzes, discussion sessions, presentations, questions proposed during the class by professors, feedback given by standardized Patients (SP) and instructors during ICM (Introduction to Clinical Medicine) practice sessions \& labs.

The current structure of summative assessment for each course is uniform in the basic science MD program. Individual courses are assessed through three summative exams in a semester period.

A questionnaire was designed with 5 different questions in the form of statements (see appendix). Answers were recorded with 5 possible options for each question (using likert scale) as shown in the result tables.

Students were re-explained the terms 'formative assessment' and 'summative assessment' with examples of activities carried out at this institution. The sole purpose of terminology definition was to avoid confusion that may occur. Pre-testing was completed on 20 randomly selected students from the same study population. All students were randomized prior to conducting the study. Only those who were willing to fill-up the questionnaire were included in the study. Students of $1^{\text {st }}$ semester of basic science courses were excluded with an assumption that they are not fully adapted to the existing assessment design at the institution. Students who were not available and were not willing to participate were excluded as well. The purpose of the study as well as the information and identity of the respondents were kept confidential. Written consents were sought duly from the students \& authority. The questionnaire was sent through Google online form and data was collected, processed and analyzed.

\section{RESULTS}

Among the total number of participants (142) in the current study, $50 \%$ were second \& third semester students who had mean learning experience of ten months in basic science 
MD program. Remaining 50\% were fourth \& fifth semester students having mean learning experience of 18 months in the same program. Results as shown in the Table 1 reveals that $25 \%$ students strongly agreed and $53 \%$ agreed with the statement that; gaps in the learning (what the students already know in compare to what they need to know) can be identified by formative assessment and thereby can be filled up by further preparation for summative assessment. Only a small percent of respondents strongly disagreed $(2 \%) \&$ disagreed $(1 \%)$ with the aforesaid statement.

Among the total number of respondents, $25.3 \%$ strongly agreed and $51.5 \%$ agreed that; through formative assessment, faculty identified various weak points of the students and thereby planned to give appropriate feedback to the students for further improvement in summative assessment (Table 2).

Students were asked about whether or not formative assessment encourages their deep learning, which in turn improves their performance in summative assessment. Result shows that; $26.3 \%$ strongly agreed whereas $54.5 \%$ agreed with the statement. On the other hand 7.1\% disagreed and $2 \%$ strongly disagreed with this point (Table 3).

In response to the statement; frequent formative assessment negatively impacts students' performance in summative assessment, $7.1 \%$ and $29.3 \%$ of the students strongly agreed and agreed respectively in their opinion (Table 4).

Opinion was sought from the students with regards to the need for well-structured method(s) of formative assessment in the medical programs; $33.3 \%$ strongly agreed and $55.6 \%$ agreed with the statement (Table 5).

\section{DISCUSSION}

Medical program at any organization must have an excellent teaching-learning environment and valid assessment system. Formative assessment particularly has a significant role to improve students' outcome. ${ }^{5}$ It helps the instructors to identify students' deficiencies and remediate those accordingly. ${ }^{9}$ However, this current study particularly shows whether or not formative assessment helps the students to identify their own deficiencies and fix it by themselves. In our study, students by large, (78\% strongly agreed and agreed) considered that formative assessment helps them to identify their learning gaps so that they can fill it up.

The term "feedback loop" in the formative assessment includes 3 components: 1) what good performance is, 2) how current performance is related to good

\begin{tabular}{|c|c|}
\hline \multicolumn{2}{|c|}{$\begin{array}{l}\text { Table 1: Students' distribution on the basis of } \\
\text { different level of opinion in response to the } \\
\text { statement; students identify their learning gaps } \\
\text { through formative assessment and thereby } \\
\text { try to fill it by further extended efforts for } \\
\text { summative assessment }\end{array}$} \\
\hline Different level of opinion & Students' response (\%) \\
\hline Strongly disagree & 2 \\
\hline Disagree & 1 \\
\hline Neither agree nor disagree & 19 \\
\hline Agree & 53 \\
\hline Strongly agree & 25 \\
\hline Total $\left(n^{*}=142\right)$ & 100 \\
\hline
\end{tabular}

\begin{tabular}{lc} 
Table 2: Students' distribution on the basis of \\
different level of opinion in response to the \\
statement; through formative assessment, \\
teachers identify students' weak points and \\
thereby provide appropriate feedback for future \\
improvement in summative assessment \\
\hline Different level of opinion & Students' response (\%) \\
\hline Strongly disagree & 2 \\
Disagree & 9.1 \\
Neither agree nor disagree & 12.1 \\
Agree & 51.5 \\
Strongly agree & 25.3 \\
Total $\left(\mathrm{n}^{*}=142\right)$ & 100 \\
\hline
\end{tabular}

\begin{tabular}{lc} 
Table 3: Students' distribution on the basis of \\
different level of opinion in response to the \\
statement; formative assessment encourages \\
the students for deep learning which in turn \\
improves the result in summative assessment \\
\hline Different level of opinion & Students' response (\%) \\
\hline Strongly disagree & 2 \\
Disagree & 7.1 \\
Neither agree nor disagree & 10.1 \\
Agree & 54.5 \\
Strongly agree & 26.3 \\
Total $\left(\mathrm{n}^{*}=142\right)$ & 100 \\
\hline
\end{tabular}

\begin{tabular}{lc} 
Table 4: Respondent distribution on the basis \\
of different level of opinion in response to the \\
statement; frequent formative assessment \\
negatively impacts students' performance in \\
summative assessment \\
\hline Different level of opinion & Students' response (\%) \\
\hline Strongly disagree & 13.1 \\
Disagree & 33.3 \\
Neither agree nor disagree & 17.2 \\
Agree & 29.3 \\
Strongly agree & 7.1 \\
Total $\left(\mathrm{n}^{*}=142\right)$ & 100 \\
\hline
\end{tabular}

performance, and 3) formulating feedback to close the gap between current and good performance. ${ }^{14}$ 


\begin{tabular}{lc} 
Table 5: Respondent distribution on the basis \\
of different level of opinion in response to \\
the statement; Medical program needs a \\
well-structured method of formative assessment \\
\hline Different level of opinion & Students' response (\%) \\
\hline Strongly disagree & 3 \\
Disagree & 1 \\
Neither agree nor disagree & 7.1 \\
Agree & 55.6 \\
Strongly agree & 33.3 \\
Total ( $\left.\mathrm{n}^{*}=142\right)$ & 100 \\
\hline $\mathrm{n}^{*}$ Total number of respondents &
\end{tabular}

Several studies mentioned the importance of sharing the learning gap with the students once identified by faculty. ${ }^{5,11,12}$ Various tools can be used to allow the students to compare their level of performance with goal which include eliciting students' thinking through the verbal or written prompts, reviewing students' notebook or homework, or listening to small group conversations etc.

The importance of closing the gap between what students currently know and what they are expected to know was necessitated. The author mentioned that the most important issues of all kinds of formative assessment are using that information of teaching, learning and thus closing the gap. ${ }^{2}$

Major chunk of students of this current study group $(76.8 \%)$ are in opinion that through formative assessment, faculty identified students' weaknesses and thereby can plan to give appropriate feedback to students for further improvement in summative assessment.

Another study indicated that formative assessment could be an important tool for teachers and students for their academic activity. It helps to identify the areas of their strength and weakness without incurring any academic penalty. It also allow for rapid remedial action. ${ }^{13}$ Students also use the feedback received from formative assessment to monitor the strength and weakness of their performances aiming towards success in the summative assessment. ${ }^{14}$

Majority of the students (26.3\% strongly agreed and 54.5\% agreed) supported formative assessment with the statement that it encourages them for more in-depth learning. Such findings are in compliance with the outcome of previous studies which demonstrated that formative assessment encourages a deeper approach of learning. ${ }^{15-17}$

A fair number of students (36.4\%) stated that too frequent formative assessment negatively affects their performance in the summative assessment. This negative effect is primarily due to interference with students' independent learning schedule. In contrary, 46.4\% students disapproved this statement. This raises the point that there is a need for scheduling various formative assessment activities with utmost care and diligence.

Based on the results, it is observed that majority of students think that formative assessment has a positive impact on the outcome of summative assessment in the basic science medical education program.

\section{CONCLUSION}

The study revealed that formative assessment has positive effect on summative assessment in various ways. Feedback derived from formative assessment remains an important tool for the students to minimize their learning gap. Formative assessment also encourages the students for regular learning and motivates them to investigate for a deeper knowledge. However, formative assessment, if carried out too frequently, impedes students' independent learning. This may produce negative effects on summative exam. Medical program needs well-structured formative activities. The current study was carried out within a small number of students representing only one geographic region. Therefore larger studies involving students from diverge medical education systems are required to draw a globally reflective conclusion.

\section{REFERENCES}

1. Epstein R. Assessment in Medical Education. New England Journal of Medicine. 2007; 356(4):387-396.

2. Black P and Wiliam D. Assessment and Classroom Learning. Assessment in Education: Principles, Policy \& Practice 1998; 5(1):7-74.

3. McTighe $\mathrm{J}$ and O'Connor K. Seven practices for effective learning. Educational leadership 2005; 63:10-17.

4. Crooks T. The validity of formative assessment. Education on-line. 2001. Available at: http://www.leeds.ac.uk/educol/ documents/00001862.htm.

5. Black P and William D. Assessment and Classroom learning. Assessment in Education. 1999; 5:103-110.

6. Chisnall B, Vince T, Hall S and Tribe R. Evaluation of outcomes of a formative objective structured clinical examination for second-year UK medical students. International Journal of Medical Education 2015;6:76-83.

7. Mitra $\mathrm{N}$ and Barua A. Effect of online formative assessment on summative performance in integrated musculoskeletal system module. BMC Medical Education 2015;15(1):29.

8. Spolsky $B$ and Hult $F$. The handbook of educational linguistics. $1^{\text {st }}$ ed. Malden, Mass.: Blackwell Pub.; 2008.

9. Cauley $\mathrm{K}$ and McMillan J. Formative Assessment Techniques to Support Student Motivation and Achievement. The Clearing House: A Journal of Educational Strategies, Issues and Ideas. 2010; 83(1):1-6.

10. Nicol D and Macfarlane-Dick D. Formative assessment and selfregulated learning: a model and seven principles of good feedback 
practice. Studies in Higher Education 2006;31(2):199-218.

11. Butler DL and Winne PH. Feedback and self-regulated learning: a theoretical synthesis. Review of Educational Research 1995;65(3):245-281.

12. Sadler D. Formative Assessment: revisiting the territory Assessment in Education: Principles, Policy \& Practice 1998; 5(1):77-84.

13. Vaz M, Avadhany S and Rao B. Student perspectives on the role of formative assessment in physiology. Medical Teacher 1996;18(4):324-326.
14. Sadler D. Formative assessment and the design of instructional systems. Instructional Science 1989; 18(2):119-144.

15. Crooks T. The Impact of Classroom Evaluation Practices on Students. Review of Educational Research 1988;58(4):438-481.

16. Rushton A. Formative assessment: a key to deep learning?. Medical Teacher. 2005; 27(6):509-513.

17. Nicol D and Macfarlane-Dick D. Formative assessment and selfregulated learning: a model and seven principles of good feedback practice. Studies in Higher Education 2006;31(2):199-218.

\section{Authors Contribution:}

SD- Concept and design of the study, reviewed the literature, manuscript preparation and critical revision of the manuscript, statistically analyzed and

interpreted, critical revision of the manuscript; KMA- Concept, collected data and review of literature and helped in preparing first draft of manuscript, critical

revision of the manuscript, statistically analyzed and interpreted; SN- Conceptualized study, literature search; VRJ-Concept of study, collected data and review of study; SK- literature search and review of study; VS- literature search and revision of the manuscript.

Orcid ID:

Dr. Sanjib Das:@ http://orcid.org/0000-0001-9457-466X

Dr. Kusai M Alsalhanie:— http://orcid.org/0000-0002-1978-5376

Dr. Samal Nauhria:(D http://orcid.org/0000-0001-7373-2606

Dr. Vivek R Joshi: io http://orcid.org/0000-0002-0369-9502

Dr. Safeer Khan:- http://orcid.org/0000-0002-0017-7928

Dr. Vishal Surender: (1) http://orcid.org/0000-0002-0023-1613 


\section{APPENDIX}

Testing tool (questionnaire) used for the study

What is your current semester?

a. $\mathrm{MD} 2$

b. $\mathrm{MD} 3$

c. $\mathrm{MD} 4$

d. MD 5

1. Students identify their learning gaps through formative assessment and thereby try to fill it by further extended efforts for summative assessment.
a. Strongly agree
b. Agree
c. Neither agree nor disagree
d. Disagree
e. Strongly disagree

2. Through formative assessment, teachers identify students' weak points and thereby provide appropriate feedback for future improvement in summative assessment.
a. Strongly agree
b. Agree
c. Neither agree nor disagree
d. Disagree
e. Strongly disagree

3. Formative assessment encourages the students for deep learning which in turn improves the result in summative assessment.
a. Strongly agree
b. Agree
c. Neither agree nor disagree
d. Disagree
e. Strongly disagree

4. Frequent formative assessment negatively impacts students' performance in summative assessment.
a. Strongly agree
b. Agree
c. Neither agree nor disagree
d. Disagree
e. Strongly disagree

5. Medical program needs a well-structured method of formative assessment
a. Strongly agree
b. Agree
c. Neither agree nor disagree
d. Disagree
e. Strongly disagree 